Article

\title{
From Religious Belief to Intangible Cultural Heritage Tourism: A Case Study of Mazu Belief
}

\author{
Dan Yao ${ }^{1}\left(\mathbb{D}\right.$, Ke Zhang $^{1}$, Lin Wang ${ }^{2}$, Rob Law ${ }^{3}\left(\mathbb{C}\right.$ and Mu Zhang ${ }^{1, *}$ (i) \\ 1 Shenzhen Tourism College of Jinan University, Shenzhen 518053, China; yaodan@sz.jnu.edu.cn (D.Y.); \\ constancezhangke@stu2017.jnu.edu.cn (K.Z.) \\ 2 Jinan University-University of Birmingham Joint Institute, Jinan University, Guangzhou 510632, China; \\ lindsaywang@jnu.edu.cn \\ 3 School of Hotel and Tourism Management, The Hong Kong Polytechnic University, Hong Kong, China; \\ rob.law@polyu.edu.hk \\ * Correspondence: zhangmu@jnu.edu.cn; Tel.: +86-755-2693-1865
}

Received: 17 April 2020; Accepted: 18 May 2020; Published: 21 May 2020

check for updates

\begin{abstract}
Mazu belief was recognized by United Nations Educational, Scientific and Cultural Organization (UNESCO) as the Intangible cultural heritage of Humanity in 2009, which is China's first world-class folklore intangible cultural heritage. More than 5000 Mazu temples and 200 million tourists who believe in Mazu can be found worldwide. The aim of the study was to take Meizhou Island as a case study to understand the relationships among tourists' perceived value, place attachment, and revisit intention. In total, 424 tourists in Meizhou Island were surveyed and structural equation modeling was performed to test such relationships. Results show that tourists' perceived value has a significant positive impact on place attachment $(p<0.05)$, which in turn has a significant positive impact on revisit intention $(p<0.05)$. The results of bootstrap test show that the confidence intervals are $(0.001,0.328),(0.147,0.425),(0.058,0.396),(0.092,0.408)$, respectively, which do not contain 0 . Therefore, place attachment acts as a complete intermediary in the relationship between tourism resources and service value, social value, cost value, and revisit intention. The confidence interval of the direct effect of cultural value and revisit intention is $(0.193,0.501)$, which does not contain 0 , indicating that place attachment acts as a partial mediator in the relationship between cultural value and revisit intention. Findings of this study would be of use to readers of cultural tourism.
\end{abstract}

Keywords: tourists' perceived value; place attachment; revisit intention; Mazu belief; intangible cultural heritage

\section{Introduction}

Intangible cultural heritage is part of the discourse on sustainable tourism for destination [1]. Intangible cultural heritage can be used as a symbol of a tourist destination to attract tourists [2]. Isfahan (Iren) as a new tourist attraction of intangible cultural heritage, can attract new tourists [3]. Meizhou Island in Putian, China is famous for its intangible cultural heritage-Mazu belief and has attracted thousands of believers to this destination [4]. However, the competition in China's tourism market has grown intensive in recent years. Despite its innate resource advantages, Meizhou Island still faces a dilemma in retaining its tourists while increasing their revisit rate.

Prior studies on revisit intention have failed to clarify the relationship between tourist satisfaction and revisit intention. Kozak [5] identified destination satisfaction as the strongest predictor of tourists revisiting the same holiday destination. By constructing a determinant model of revisit intention, Petrick, Morais, and Norman found that satisfaction directly affects revisit intention and indirectly affects revisit intention through perceived value [6]. Weng believed that satisfaction has a lasting 
effect on the psychology of tourists and significantly affects their revisit intention [7]. Fakeye and Crompton argued that visitors choose to revisit the same tourist destination not necessarily because of high satisfaction [8]. Oppermann found that those tourists who are dissatisfied with a tour choose to revisit a destination given the lower risks in visiting a familiar place than in visiting a new place [9]. However, some scholars show that satisfaction does not encourage the revisit intention of tourists. Liu found that cultural attractions such as museums have difficulty in providing tourists with a new travel experience. Even if tourists are very satisfied, their willingness to revisit is not high [10]. Moreover, using satisfaction theory to analyze the formation of revisit intention among tourists is not ideal, and taking new research perspectives into account is not necessary in explaining revisit intention comprehensively.

In the case study of George Town and Melaka, Tan et al. found that person-place bonding (place attachment) may contribute to the sustainability of intangible cultural heritage and the development of destination sustainable tourism [11]. Based on the intangible cultural heritage-Mazu belief, this unique study uses a novel approach that combines perceived value with place attachment theory to explore the impact of revisit intention. A major contribution of this study is to promote the sustainable development of tourist destinations of intangible cultural heritage.

\section{Literature Review}

\subsection{Tourists' Perceived Value}

Tourism researchers examined perceived value and generally defined tourists' perceived value from the "trade-off comparison" perspective. A representative scholar of "trade-off comparison," Zeithaml [12] defined perceptive value as "the consumer's overall assessment of the utility of a product based on perceptions of what is received and what is given." Murphy, Pritchard, and Smith argued that tourists combine the perceived quality of a destination with its price to form their perceived value [13]. The study defined tourists' perceived value. It is the tourist's overall assessment of the utility of experiencing in a certain tourist situation, which is based on perceptions of what is received and what is given. Scholars have designed different scales of tourists' perceived value for different research objects and tourist situations. For instance, in their case study of wetland parks, Wang, Zhang, and Lu proposed six dimensions of environmental, characteristic, service, management, knowledge education, and cost values [14]. In a case study of red tourism in Hunan Shaoshan, Fan identified the four dimensions of knowledge, social, functional, and emotional values [15]. In a case study of the cultural heritage of the Summer Place in Beijing, Zhou identified seven dimensions of environmental facility, landscape, participation interaction, historical and cultural, emotional, management and service, and cost values [16]. These scholars have also measured both the perceived profit (income class attribute) and the perceived profit and loss (cost class attribute). Cost class attribute has been defined in terms of money, time, and physical and mental expenditures, but given the differences in travel situations, the income class attribute presents multiple dimensions. Studies on the tourism sector have examined the perceived value of hotel services [17]. Subsequently, the value of specific tourism companies, products, or services, such as hotel websites [18], travel agency tour packages [19], cruises [20], scenic spots [21], tourist destinations [22,23], and travel experience processes, have been examined. Chen and Tsai incorporated destination image and perceived value into the "quality-satisfaction-behavior intention" paradigm and proposed a relatively complete tourism behavior model [24]. Lo and Lee explored those factors that have motivated Hong Kong tourists to participate in volunteer tourism to obtain their perceived value [25]. Eid and El-Gohary found that the six dimensions of Muslim tourists' perceived value positively affect their satisfaction [26]. Rasoolimanesh, Dahalan, and Jaafar found that perceived value has a strong positive impact on the satisfaction of boarding tourists [27]. 


\subsection{Place Attachment Theory}

Place attachment is a combination of local theory (geography) and attachment theory (psychology) proposed by Tuan [28], and he regarded the emotional connection between people and places or the environment as topophilia. Williams and Roggenbuck then defined place attachment as the individual's sense of belonging to a particular place [29]. Place attachment has been investigated by scholars in the field of leisure travel in the early 1990s, with Huang, Bao, and Wall introducing this concept in China's tourism field using the term "place dependence" [30]. Williams et al. divided place attachment into two dimensions: place identity and place dependence. Place identity is a kind of emotional attachment, which is more inclined to the emotional connection between people and places, emphasizing that individuals and places share common values, attitudes, thoughts, and beliefs. Place dependence is a kind of functional attachment, which focuses on the function of local areas to meet individual needs and goals and emphasizes a personal sense of belonging to local areas [31].

Researchers have begun to define place attachment as the connection between people and places based on emotion, cognition, and behavior [32]. The application of place attachment in the field of tourism mainly focuses on the perspectives of tourists and residents. The interaction between place attachment and tourism development is mainly studied from the residents' perspective. By conducting a survey of urban residents in Midwest U.S., Wang and Chen found that the place identity of residents significantly affects their perceptions and attitudes toward the effects of tourism [33]. Meanwhile, the influence of place attachment on tourists' revisit intention, specifically on their intention to pay, environmental protection behavioral intention, and revisit intention. Kyle, Graefe, Manning, and Bacon examined the effects of place identity and place dependence on the attitudes of tourists and services expenditures and found that place identity has a stronger effect than place dependence [34]. Halpenny found that the place attachment of park visitors is positively related to environmental protection behavioral intention [35]. Other scholars show that place attachment can directly affect tourists' revisit intention [36] or indirectly affect tourists' revisit intention through satisfaction [37] and mediates the relationship of revisit intention with other factors [38]. Therefore, this study defines place attachment as the emotional connection between people and destinations in the process of tourist experience.

\subsection{Revisit Intention}

Revisit intention can be extended to "consumer repurchase" in the field of marketing. Baker and Crompton defined revisit intention as the possibility for tourists to return to certain tourist destinations to participate in tourism activities [39]. Cole and Scott defined revisit intention as the plan of tourists to revisit a destination [40]. From the quantitative perspective, Haywood argued that the marketing cost required to attract a repeat visitor is one-fifth of that required to attract a new visitor [41]. Oppermann highlighted the importance of tourist revisit in increasing the market share of mature tourist destinations and found that attracting revisiting tourists is easier and more effective than attracting new tourists [9]. Therefore, revisit intention has become a hot topic in tourism research, with some scholars using revisit intention to predict the number of repeat visitors. Baker and Crompton argued that when a tourist had a strong intention to revisit, $\mathrm{s} /$ he would be more likely to revisit the destination [39]. Huang and Hsu replaced the repeat visitor with revisit intention [42], whereas Pan discovered that emotional and overall images significantly and positively affect the behavioral intentions of tourists, but the effects of cognitive image are not obvious [43]. In their multiple linear regression analysis, Liu and $\mathrm{Wu}$ found that the motivation of Buddhist pilgrimage and opportunities for rest and relaxation can affect tourists' revisit intention [44]. Jang and Feng found that satisfaction is a direct cause of short-term revisit intention and that seeking new motives is an important cause of mid-term revisit intention [45]. Assaker, Vinzi, and $\mathrm{O}^{\prime} \mathrm{C}$ onnor found that tourists who seek higher levels of novelty have a lower immediate revisit intention but are expected to show a higher revisit intention in the future [46]. Given that those factors that affect revisit intention have been analyzed by using data obtained from different tourist situations and destinations, some differences have been found in the results. 
Based on the analysis of prior studies, it is more practical to analyze the impact on tourist revisit intention from the perspective of "sentimental" relationship of place attachment, which is a relationship between people and place. In addition, it needs to be judged rationally. Perceived value is the result of tourists rationally measuring this travel experience. Result of literature research shows that a relationship exists among tourists 'perceived value, place attachment, and tourist revisit intention. Perceived value helps tourists foster place attachment. Studies on revisit intention should consider specific travel situations. Following the intangible cultural heritage-Mazu belief tourism situation, this study examines the manner through which the effect of tourist revisit intention emerges.

Attitude has three components, namely, cognition, emotion, and behavioral orientation. Baloglu argued that cognition, emotion, and behavioral tendencies are interrelated and hierarchical and that emotion mediates the relationship between cognition and intention [47]. Therefore, based on attitude theory and following previous research, this study uses the perceived value of tourists as a cognitive variable, place attachment as emotional and mediator variables, and revisit intention as a behavioral bias variable. A conceptual model of the effect of tourists' perceived value on the travel destination of Mazu belief is re-established as shown in Figure 1. According to Mazu belief, the tourists' perceived value can be divided into four dimensions, namely, tourism resources and service, cultural, social, and cost values, whereas place attachment can be divided into two dimensions, namely, place identity and place attachment.

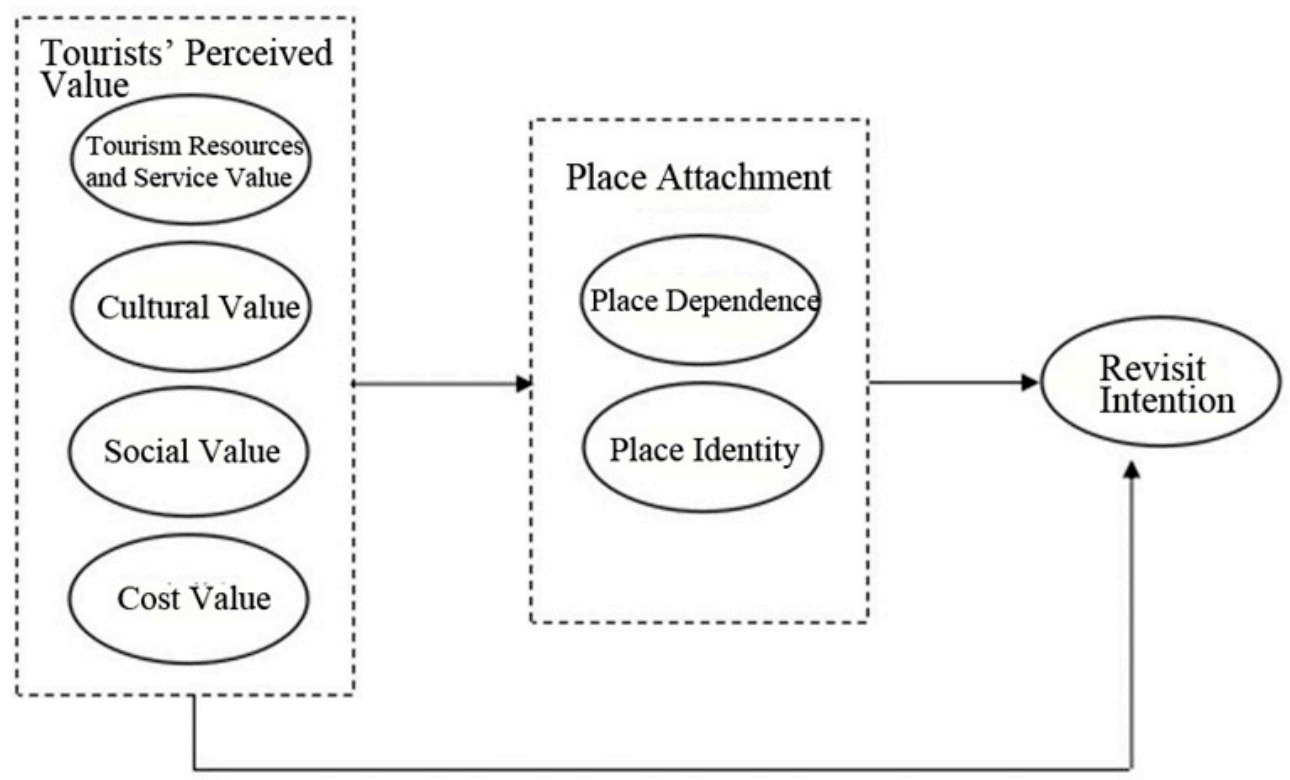

Figure 1. Conceptual model of tourists' perceived value, place attachment, and revisit intention.

Some scholars argue that perceived value affects future behavioral intentions through satisfaction $[48,49]$, whereas others believe that perceived value is a better predictor of repurchase intention than satisfaction [50-52]. To explore the relationship between perceived value and revisit intention, the following hypotheses are proposed:

Hypothesis 1 (H1). Tourists' perceived value and revisit intention have a significantly positive impact.

Hypothesis 1a (H1a). The value of tourism resources and services has a significantly positive impact on revisit intention.

Hypothesis $\mathbf{1 b}(\mathbf{H 1 b})$. Cultural value has a significantly positive impact on revisit intention.

Hypothesis 1c (H1c). Social value has a significantly positive impact on revisit intention. 
Hypothesis 1d (H1d). Cost value has a significantly positive impact on revisit intention.

Ji [53] modeled the relationship among tourists' perceived value, place attachment, and environmentally responsible behavior and found that the five dimensions of tourists' perceived value (i.e., service, emotional, cost value, environmental, and facility values) have positive and significant impacts on place attachment. This study explores whether the dimensions of tourists' perceived value of a cultural tourism tour affect their place attachment. The following hypotheses are then proposed:

Hypothesis 2 (H2). Tourists' perceived value and place attachment have significantly positive impacts on tourism.

Hypothesis 2a (H2a). The value of tourism resources and services has a significantly positive impact on place dependence.

Hypothesis $\mathbf{2 b} \mathbf{( H 2 b ) . ~ C u l t u r a l ~ v a l u e ~ h a s ~ a ~ s i g n i f i c a n t l y ~ p o s i t i v e ~ i m p a c t ~ o n ~ p l a c e ~ d e p e n d e n c e . ~}$

Hypothesis 2c (H2c). Social value has a significantly positive impact on place dependence.

Hypothesis $\mathbf{2 d} \mathbf{( H 2 d )}$. Cost value has a significantly positive impact on place dependence.

Hypothesis 2e (H2e). Tourism resources and service value have significantly positive impacts on place identity.

Hypothesis $2 \mathbf{f}$ (H2f). Cultural value has a significantly positive impact on place identity.

Hypothesis $2 \mathbf{g}(\mathbf{H} 2 \mathbf{g})$. Social value has a significantly positive impact on place identity.

Hypothesis $2 \mathbf{h}(\mathbf{H} 2 \mathbf{h})$. Cost value has a significantly positive impact on place identity.

Previous studies also show that place attachment highlights the emotional bonds between tourists and destinations and affects tourist revisit intention. To explore such a relationship, the following hypotheses are proposed:

Hypothesis 3 (H3). Tourists' place attachment and revisit intention have significantly positive impacts on cultural tourism destinations.

Hypothesis 3a (H3a). Place dependence has a significantly positive impact on revisit intention.

Hypothesis $\mathbf{3 b} \mathbf{( H 3 b ) . ~ P l a c e ~ i d e n t i t y ~ h a s ~ a ~ s i g n i f i c a n t l y ~ p o s i t i v e ~ i m p a c t ~ o n ~ r e v i s i t ~ i n t e n t i o n . ~}$

The tourists' perceived value of tourism destinations promotes their place attachment, and a strong sense of attachment helps stimulate their revisit intention. Baloglu argued that emotions mediate the relationship between cognition and intention [46]. Therefore, the following hypotheses are proposed:

Hypothesis 4 (H4). Place attachment mediates the effect of tourists' perceived value on their intention to revisit cultural destinations.

Hypothesis 4a (H4a). Place attachment mediates the effect of tourism resources and services on tourists' revisit intention.

Hypothesis $4 \mathbf{b}(\mathbf{H} 4 \mathbf{b})$. Place attachment mediates cultural value, which plays a role in revisit intention. 
Hypothesis 4c (H4c). Place attachment mediates social value, which plays a role in revisit intention.

Hypothesis $4 \mathbf{d}(\mathbf{H} 4 \mathbf{d})$. Place attachment mediates cost value, which plays a role in revisit intention.

\section{Methodology}

\subsection{Case Seclection}

Located in Putian City in Fujian Province, Meizhou Island has a long terrain shaped like a frown and is also known as "Southern Penglai." Mazu Temple is the major tourist attraction in the island. Meizhou Island also serves as the hometown of Mazu and the birthplace of Mazu culture. The pilgrimage to Meizhou Island is often grand during Mazu's anniversary (March 23 of the lunar calendar) and Mazu Sheng Day (September 9 of the lunar calendar). Nearly 200 million Mazu tourists from more than 20 countries and regions around the world dream and pay homage in sacred places known as "Oriental Mecca." The Mazu Temple was built the same year when Mazu died. After several years of expansion, the temple was named as a National Key Cultural Relics Protection Unit in 2006. In the same year, approved by the state council of the People's Republic of China, Mazu festival is one of the first instances of intangible cultural heritage recognized by the ministry of culture.

Tourism is the pillar industry of Meizhou Island, which makes full use of Mazu cultural tourism resources to develop itself into a tourist resort that integrates pilgrimage, leisure, sightseeing, experience, and vacation. In January 2016, the National Tourism Administration included Meizhou Island in its list of China's international tourism destinations. Meizhou Island has also obtained three national-level certifications, including "National Tourism Resort," "National Scenic Area," and "National Ocean Park." In 2018, the tourism revenue of Meizhou Island reached 4.1 billion RMB, representing a 16.8\% year-on-year growth, and 6.72 million domestic and foreign tourists, representing a $19.4 \%$ increase. Meizhou Island has fully exploited its Mazu cultural tourism resources to attract tourists. Therefore, the island has become a representative local and global tourist destination.

\subsection{Questionnaire Design and Pre-Investigation}

To verify the hypotheses, this study investigated Meizhou Island, as the origin of "Mazu belief," as a case study. By combining the variables and dimensions examined in previous studies, this research used a five-point Likert scale for the data collection and constructed pre-study questionnaires with three variables and 29 measurement indicators for tourists' perceived value, place attachment, and revisit intention. It is a Chinese questionnaire and the respondents fill it in Chinese. The dimensions of each variable and the sources of the measurement items are listed as follows:

1. This study divides tourists' perceived value of cultural heritage tourism into four dimensions, namely, tourism resources and service, cultural, social, and cost values. The specific measurement items and reference sources are shown in Table 1.

2. This study divided place attachment into place dependence and place identity. Previous scholars used high-frequency measurement items from specific research contexts to design their measurement problems. The specific measurement items and reference sources used in this study are listed in Table 2.

3. Revisit intention includes the tourists' interest and possibility of revisiting a destination. Revisit intention prioritizes tourists' intention to revisit the same type of destination. The specific measurement items and reference sources are shown in Table 3.

The pre-survey questionnaire included 29 item scales and demographic information. Before the field investigation of Meizhou Island, the research was approved by the Management Committee of Meizhou Island National Tourism Resort. From 13 January to 14 January 2019, 100 questionnaires were issued prior to conducting the case study in Meizhou Island, and an effective response rate of $91 \%$ was 
obtained. Among the respondents, 42 were male and 49 were female. After the SPSS 22.0 analysis, the two items with an initial corrected item-total correlation (CITC) value of less than 0.4 were omitted. An exploratory factor analysis was then performed on the remaining 27 items to test the construct validity of the questionnaire. The variable validity was greater than 0.7 , thereby indicating that the questionnaire was suitable for the factor analysis. The questionnaire item descriptions and adjustment items were corrected to form the 27 measurement items used in the first part of the questionnaire. The second part was used to collect the demographic information of the respondents.

Table 1. Measurement items for tourists' perceived value.

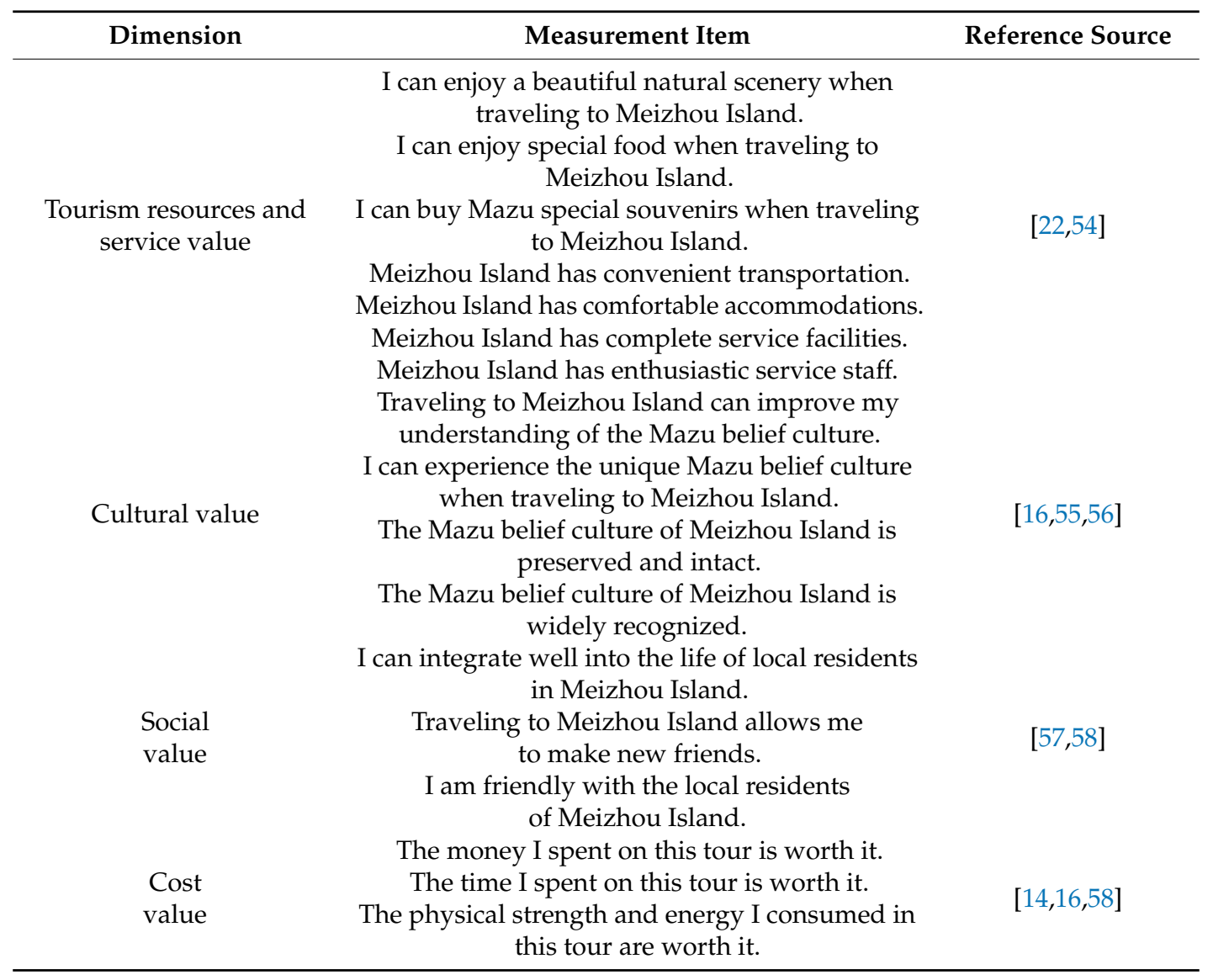

Table 2. Measurement items for place attachment.

\begin{tabular}{ccc}
\hline Dimension & Measurement Item & Reference Source \\
\hline & $\begin{array}{c}\text { I get more satisfaction from experiencing Mazu } \\
\text { belief in Meizhou Island than from experiencing } \\
\text { it in other places. } \\
\text { Place dependence }\end{array}$ & $\begin{array}{c}\text { Meizhou Island gives me a feeling that I cannot } \\
\text { feel in other places. } \\
\text { This is the best place for me to do } \\
\text { what I enjoy doing. }\end{array}$ \\
[33,59-62] \\
No faithful tourist destination can compare to \\
Meizhou Island. \\
I identify strongly with the Mazu belief culture of \\
Meizhou Island. \\
Meizhou Island is very special to me. \\
I feel like Meizhou Island is a part of me. \\
I am very attached to Meizhou Island.
\end{tabular}


Table 3. Measurement items for revisit intention.

\begin{tabular}{ccc}
\hline Dimension & Measurement Item & Reference Source \\
\hline & I am interested in revisiting Meizhou Island. & \\
I may come to Meizhou Island again in the future. & \\
Revisit intention & $\begin{array}{l}\text { I will travel to Meizhou Island more frequently. } \\
\text { Meizhou Island is my first destination choice } \\
\text { when I wish to experience Mazu belief. }\end{array}$ & {$[16,63,64]$} \\
\hline
\end{tabular}

\subsection{Questionnaire Collection, Reliability, and Validity Testing}

The formal survey was conducted in Meizhou Island, Putian from February 18 to 25, 2019, where 500 questionnaires were distributed by convenience sampling. After obtaining the consent of the tourists, the questionnaire survey was conducted. A total of 424 valid responses were received, representing an effective response rate of $84.8 \%$. According to the results of the SPSS 22.0 analysis, the Cronbach's alpha value of the 27 measurement items in the formal questionnaire was 0.966 , whereas those for tourists' perceived value, place attachment, and revisit intention scale were $0.944,0.946$, and 0.961 , respectively, thereby indicating good reliability. In the validity test, the Kaiser-Meyer-Olkin (KMO) values of the tourists' perceived value, place attachment, and revisit intention subscales were $0.925,0.902$, and 0.782 , respectively, and the significant probability of the Bartlett's spherical test was 0.000 , thereby indicating that the scale is suitable for the factor analysis.

\section{Result}

\subsection{Demographic Information}

A total of 424 valid questionnaires were collected. Among the respondents, 205 were male and 219 were female. The effective sample of males and females was similar, with young and middle-aged respondents having a high tourist cultural level comprising the majority of the sample. The majority of the respondents had an average monthly salary of 3000 to 5000 yuan, followed by respondents with a monthly salary of below 3000 yuan. In terms of occupation, the majority of the respondents were employees of private companies (37.3\%), followed by employees of government agencies or institutions, which match the average monthly salary and education levels of tourists. Approximately $33.8 \%$ of the respondents came from Putian City, whereas 29.8\% came from other cities in Fujian Province. Nearly $50 \%$ of the respondents were repeating visitors of Meizhou Island, among whom $30.7 \%$ visited the island for the second time, $12 \%$ visited the island for the third time, and $6.7 \%$ visited the island more than three times. In terms of stay duration, $53.3 \%$ of the respondents planned to stay for two days, $32.2 \%$ were on a daytrip, and $2.7 \%$ were planning to stay on the island for more than three days, thereby suggesting that tourists of Meizhou Island are mostly short-time visitors. In terms of familiarity with the Mazu belief, $48.8 \%$ of the respondents mentioned that they are interested in Mazu yet are generally unfamiliar with such belief. They traveled to Meizhou Island to experience Mazu culture.

\subsection{Exploratory Factor Analysis}

A principal component analysis was conducted to obtain the four factors of the tourists' perceived value subscale with an eigenvalue of greater than 1 and cumulative variance interpretation rate of $76.244 \%$. The place attachment subscale with an eigenvalue greater than 1 had two factors and a cumulative variance interpretation rate of $84.376 \%$. Only one factor of the revisit intention subscale had an eigenvalue of greater than 1 and a cumulative variance interpretation rate of $92.939 \%$. The cumulative variance interpretation of the three subscales exceeded $50 \%$, and those items corresponding to each dimension were attributed to the same factor without the need to delete this factor. In sum, the various measurement items of the three subscales had good stability and internal consistency. 


\subsection{Confirmatory Factor Analysis}

The exploratory factor analysis revealed that tourists' perceived value is a four-dimensional variable with a two-layered latent variable structure. The first- and second-order confirmatory factor analyses obtained $X^{2} / \mathrm{df}=2.237$, Root Mean Square Error of Approximation (RMSEA) $=0.047$, Goodness of Fit Index (GFI) $=0.984$, Normed Fit Index $(\mathrm{NFI})=0.926$, Incremental Fit Index $(\mathrm{IFI})=0.958$, Comparative Fit Index $(\mathrm{CFI})=0.957$, and Adjusted Goodness of Fit Index (AGFI) $=0.886$, thereby suggesting an acceptable goodness of fit between the items of the measurement model and the four dimensions of tourists' perceived value. In addition, given that place attachment is a 2D variable, only a first-order confirmatory factor analysis was performed, which yields $\mathrm{X}^{2} / \mathrm{df}=2.934$, RMSEA $=0.053, \mathrm{GFI}=0.944, \mathrm{NFI}=0.973, \mathrm{IFI}=0.982, \mathrm{CFI}=0.982$, and AGFI $=0.888$, thereby indicating a favorable goodness of fit between the two items of the measurement model and place attachment. Revisit intention is a 1D variable tested by three items. The critical value ratio of the three subscales exceeded 1.96 and was significant at $p<0.001$. Meanwhile, the normalized factor loading of the 27 items exceeded 0.4 , the combined reliability of each dimension exceeded 0.7 , the average variance extraction value exceeded 0.5 , and the correlation coefficient between each item was less than its average variance extraction value of the item, thereby suggesting that the three subscales had good aggregation validity.

\subsection{Structural Equation Model and Hypothesis Testing}

The initial conceptual model constructed in the previous article was verified by using AMOS 21.0, and 7 latent variables and 27 measurement index normalized factor loadings were obtained. The model obtained $\mathrm{X}^{2} / \mathrm{df}=2.340, \mathrm{RMSEA}=0.077, \mathrm{NFI}=0.910, \mathrm{IFI}=0.947, \mathrm{CFI}=0.946, \mathrm{GFI}=0.804$, and AGFI $=0.757$, thereby suggesting that although the initial structural model had a favorable goodness of fit, the individual indicators failed to meet the standard and a model correction should be performed.

Table 4 shows that 10 of the 14 hypotheses are supported. The absolute value of the critical ratios of "H1a: revisit intention $\leftarrow$ tourism resources and service value," "H1c: revisit intention $\leftarrow$ social value," and "H1d: revisit intention $\leftarrow$ cost value" were less than 1.96 , whereas their $p$-values were much greater than 0.05 . Therefore, these three paths were deleted for model correction. Meanwhile, the critical ratio of "H2g: place identity $\leftarrow$ social value" was 1.693 , which was slightly less than 1.96, and the $p$-value was 0.091 , which was near 0.05 . Therefore, this path was preserved for the time being.

Table 4. Results of the modified structural model path analysis.

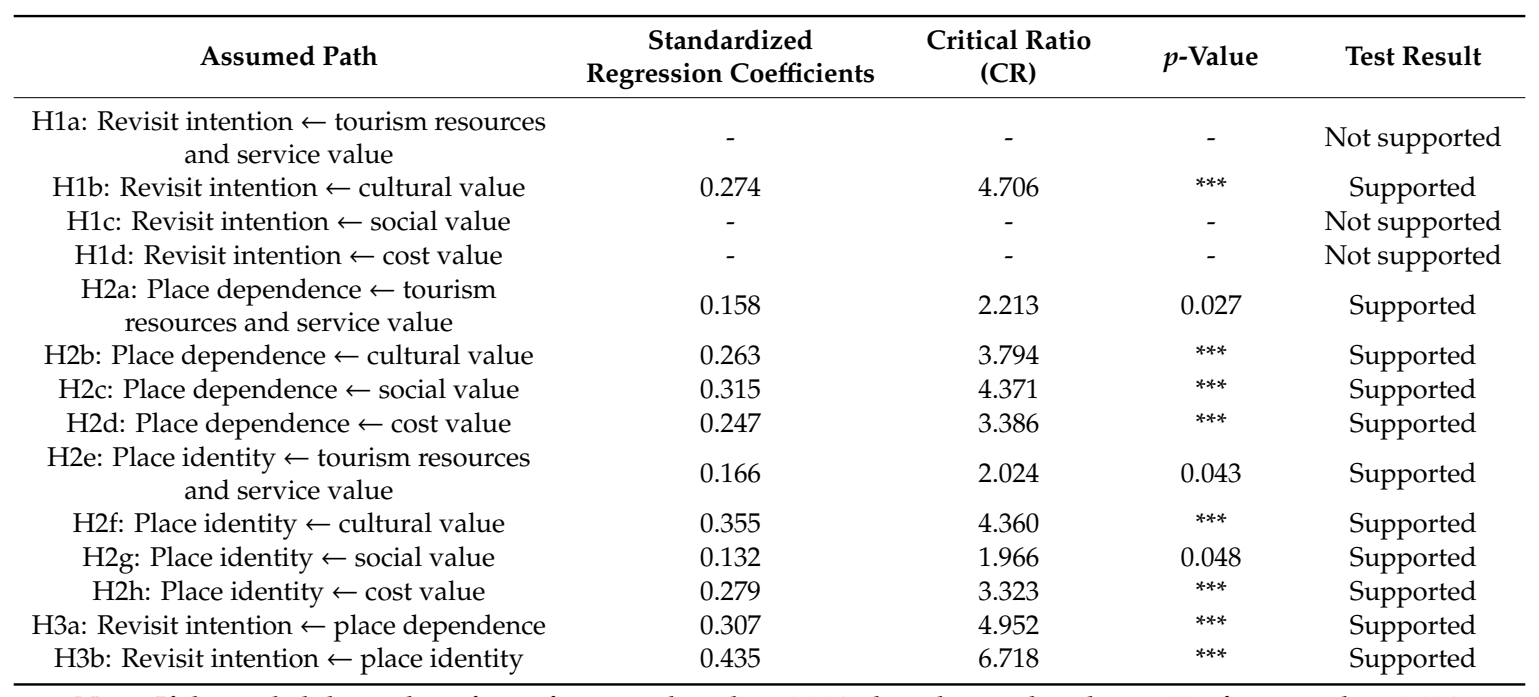

Note: If the probability value of significance is less than 0.001 , then the $p$-value shows ${ }^{* * *}$; if greater than 0.001 , then the $p$-value directly presents the numerical value. 
The corrected model obtained $\mathrm{X}^{2} / \mathrm{df}=2.323, \mathrm{RMSEA}=0.077, \mathrm{GFI}=0.904, \mathrm{NFI}=0.910, \mathrm{IFI}=0.947$, $\mathrm{CFI}=0.946$, and AGFI $=0.859$, thereby indicating that the modified structural model has a favorable goodness of fit. The results of the modified structural model path analysis are shown in Table 4 . "H2g: place identity $\leftarrow$ social value" also passed the test, and 11 of the 14 validated hypotheses were supported. The final structural model is shown in Figure 2.

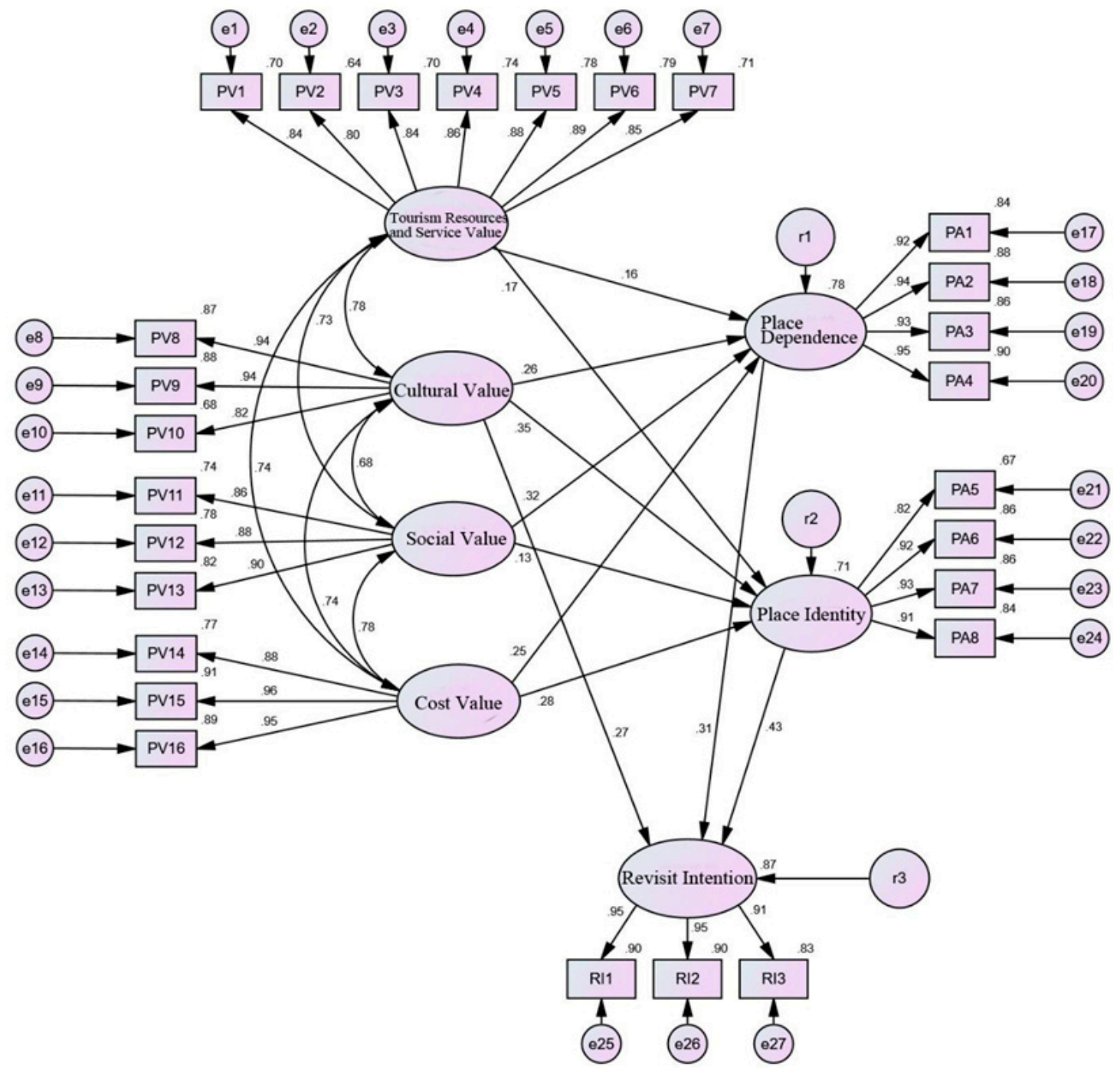

Figure 2. Final structural model.

\subsection{Mediating Effect Test}

The bootstrap method of the AMOS software was used to test the mediation effect. Tourism resources, service value, social value, and cost value had no direct effects on revisit intention yet had indirect effects on revisit intention through place dependence and place identity. Meanwhile, cultural value directly affected revisit intention and indirectly affected revisit intention through place dependence and place identity. The bootstrap analysis results show that the confidence intervals of tourism resources, service value, cultural value, social value, and cost value on the indirect effect of revisit intention were $(0.001,0.328),(0.147,0.425),(0.058,0.396)$, and $(0.092,0.408)$, respectively. None of these intervals is zero, thereby indicating that the two dimensions of place attachment mediate the relationships of tourism resources with service value, cultural value, social value, cost value, and revisit intention. The confidence interval for the direct effect of cultural value on revisit intention was $(0.193$, 0.501), suggesting that the direct effect of cultural value on revisit intention is also significant. The two 
dimensions of place attachment act as part mediators between cultural values and revisit intention. Therefore, hypotheses H4a to H4d are supported.

\section{Discussion}

From Mazu belief to sustainable tourism of intangible cultural heritage, revisit intention is a key research issue. Based on the attitude theory, a model of influencing factors of tourists' revisiting intention in intangible cultural tourism destinations was constructed and revealed the relationship among tourists' perceived value, place attachment, and revisit intention by empirical research. The effect of tourists' perceived value on place attachment, along with the four dimensions of tourism resources and service value, cultural value, social value, and cost value, has a significantly positive influence on place dependence and place identity. The study is not only consistent with the literature that tourists' perceived value has a significantly positive effect on place attachment [53,65], but also expands the two dimensions of place attachment: place dependence and place identity. Therefore, meeting the needs of tourists allows them to obtain perceived value and fosters their place attachment.

Place dependence and place identity have significantly positive effects on revisit intention, with place identity showing a greater impact. This is different from previous literature. When Bai studied rural tourists, he found that place dependence had a significantly positive effect on loyalty, but place identity did not [60]. When Ding et al. studied Zhouzhuang tourists, they found the opposite conclusion: place identity had a significantly positive effect on revisit intention, but place dependence did not [66]. Some differences can be observed between place dependence and place identity. Therefore, place attachment is divided into two dimensions to further understand the place attachment degree of tourists.

Cultural value has a significantly positive influence on revisit intention, whereas tourism resources and service value, social value, and cost value have no direct effects. This is different from the previous literature. Chen found that tourism resources, service value, and emotional value are important factors influencing revisit intention [54]. Under different tourist situations, tourists show different perceived value dimensions, and the emphasis on these dimensions also differs. In the context of religious culture and tourism, cultural value is the most interesting for tourists and significantly affects their revisit intention.

Place attachment is an important tool to understand tourists' behavior and plays a moderating role in tourists' revisit intention [67]. Place attachment is manifested in its intermediary effect on the relationship between tourists' perceived value and revisit intention. These two dimensions of place attachment also mediate the relationship of tourism resources with service value, cultural value, social value, cost value, and revisit intention. Among them, place attachment acts as a complete intermediary between tourism resources and service value, social value, cost value, and revisit intention and shows a partially mediating effect on the relationship between cultural values and revisit intention.

\section{Conclusions}

This study combines perceived value with place attachment theory in examining Meizhou Island in Putian, the origin of the "Mazu belief." Following the cognitive-emotion-behavioral intentions path of attitude theory, tourists' perceived value was used as a cognitive variable, place attachment was used as an emotional variable, and revisit intention was used as a behavioral intention variable to construct a model that describes and verifies the effects of tourists' perceived value and place attachment on their revisit intention in the context of cultural heritage tourism. Meizhou Island can improve its tourist revisit rates in three ways. First, the island should improve its tourism facilities and services and enhance the tourists' perceived value. The survey data show that tourists have a low level of perceived value for the available tourism resources and services in Meizhou Island. Therefore, the destination should produce tourist souvenirs infused with Mazu culture characteristics. The speeding setup of speedboats and ships strictly control the operation of battery cars on the island to ensure the safety of tourists. Mazu feast dishes rely on color and fragrance to attract tourists. Therefore, the destination 
should organize professional knowledge training for its tourism service personnel, improve their professional literacy, and think of other ways to enhance the tourists' perception of their tourism resources and service value. Second, the island should pay attention to the value of Mazu culture and improving its tourism quality. The survey shows that Meizhou Island lacks interactive cultural products that can mobilize the sensory organs of tourists, thereby preventing these tourists from learning about the Mazu culture. Therefore, Meizhou Island should attach great importance to the cultural value of Mazu belief. Despite taking the cultural elements of Mazu as its main axis, the island should develop tourism products or organize events with cultural creativity to meet the needs of tourists, such as the Summer Beach Music Festival in Pazhou, flying luminous 3D kites, and Mazu story sand sculptures. Third, the island should enrich the Mazu tourism experience of the tourists and cultivate their place attachment. By promoting regional cooperation in Meizhou Island, the Mazu tourism brand can attract tourists, extend their stay, and gradually cultivate their place attachment.

Tourists' intention to revisit Meizhou Island is above average, yet it shows a large standard deviation. These tourists also demonstrate certain differences. Future studies should classify the tourists in a tourist destination, compare their perceived values and place attachment levels, and understand the reasons behind the differences in their revisit intention to develop highly specific and effective suggestions that can motivate these tourists to revisit. Sustainable cities and communities are one of UNESCO's sustainable development goals, which can be achieved by improving resource utilization and reducing pollution. Sustainability is acknowledged as a balanced and constructive link among heritage conservation, tourism, and economic development [68]. As an independent concept, sustainability provides a general direction for tourist destinations [11]. The competitiveness of the tourism industry is closely linked to local sustainability, as the quality of a tourist destination is strongly influenced by its natural and cultural heritage [68]. Cultural heritage can attract more tourists than other tourism spots [69]. Tourist destination can achieve a more sustainable economy partly by developing tourism based on cultural heritage. Intangible cultural heritage is a potential precious resource for the development of cultural tourism [70]. Place attachment promotes sustainable development, especially intangible cultural heritage tourism [11]. Meizhou Island is a tourist destination of intangible cultural heritage. Mazu culture is special and international. Based on place attachment, studying tourists' revisit behavior in the context of belief and customs is of international importance for the sustainable development of tourist destinations and can inspire further research into intangible cultural heritage tourism and the religious-belief-related tourism in other countries and regions. By promoting the tourism development of intangible cultural resources and making full use of intangible cultural resources in tourism destinations, this study is in line with the sustainable urban and community development goals of UNESCO.

Author Contributions: Conceptualization, M.Z.; funding acquisition, M.Z.; investigation, D.Y., K.Z., and L.W.; methodology, D.Y., L.W., and R.L.; writing-original draft, D.Y., K.Z., and L.W.; writing一review and editing, D.Y., R.L., and M.Z. All authors have read and agreed to the published version of the manuscript.

Funding: This research was funded by the National Social Science Foundation of China (grant number: 16AZD055).

Conflicts of Interest: The authors declare no conflict of interest.

\section{References}

1. Lonardi, S.; Martini, U.; Hull, J.S. Minority languages as sustainable tourism resources: From Indigenous groups in British Columbia (Canada) to Cimbrian people in Giazza (Italy). Ann. Tour. Res. 2020, 102859. [CrossRef]

2. Deacon, H. Intangible heritage in conservation management planning: The case of Robben Island. Int. J. Herit. Stud. 2004, 10, 309-319. [CrossRef]

3. Masoud, H.; Mortazavi, M.; Farsani, N.T. A study on tourists' tendency towards intangible cultural heritage as an attraction (case study: Isfahan, Iran). Cityculture Soc. 2019, 17, 54-60. [CrossRef]

4. Putian Culture Network. Available online: http://www.ptwhw.com/?post=4580 (accessed on 19 July 2012).

5. Kozak, M. Repeaters' behavior at two distinct destinations. Ann. Tour. Res. 2001, 28, 784-807. [CrossRef] 
6. Petrick, J.F.; Morais, D.D.; Norman, W.C. An examination of the determinants of entertainment vacationers' intentions to revisit. J. Travel Res. 2001, 40, 41-48. [CrossRef]

7. Weng, L. Analysis of Tourists' re-parade in Shanghai suburbs. Tour. Sci. 2005, 19, 33-37. [CrossRef]

8. Fakeye, P.C.; Crompton, J.L. Image differences between prospective, first-time, and repeat visitors to the Lower Rio Grande Valley. J. Travel Res. 1991, 30, 10-16. [CrossRef]

9. Oppermann, M. Destination threshold potential and the law of repeat visitation. J. Travel Res. 1998, 37, 131-137. [CrossRef]

10. Liu, J. Behavioral Research on the Museum Visitor: A Case Study on Museum of the Western Han Dynasty Mausoleun of the Nanyue King, Guangzhou. J. Guilin Inst. Tour. 2005, 16, 40-44.

11. Tan, S.K.; Tan, S.H.; Kok, Y.S.; Choon, S.W. Sense of place and sustainability of intangible cultural heritage-The case of George Town and Melaka. Tour. Manag. 2018, 67, 376-387. [CrossRef]

12. Zeithaml, V.A. Consumer perceptions of price, quality, and value: A means-end model and synthesis of evidence. J. Mark. 1988, 52, 2-22. [CrossRef]

13. Murphy, P.; Pritchard, M.P.; Smith, B. The destination product and its impact on traveller perceptions. Tour. Manag. 2000, 21, 43-52. [CrossRef]

14. Wang, L.; Zhang, H.; Lu, L. Study on tourist perceived value in Wetland Park: A case study of Xixi / Wuhu. Tour. Trib. 2014, 29, 87-96. [CrossRef]

15. Fan, C.C. A Study on Red Tourism Motivation, Perceived Value and Behavioral Intention Relationship. Master's Thesis, Hunan Normal University, Changsha, China, 2014.

16. Zhou, C. A Study on the Influence of Tourist Perceived Value on the Revisit Intention in Historical Heritage Sites. Master's Thesis, Beijing Forestry University, Beijing, China, 2016.

17. Kwun, J.W.; Oh, H. Effects of brand, price, and risk on customers' value perceptions and behavioral intentions in the restaurant industry. J. Hosp. Leis. Mark. 2004, 11, 31-49. [CrossRef]

18. Abdullah, D.; Jayaraman, K.; Kamal, S.B.; Md Nor, N. A conceptual model of interactive hotel website: The role of perceived website interactivity and customer perceived value toward website revisit intention. Procedia Econ. Financ. 2016, 37, 170-175. [CrossRef]

19. Sanchez, J.; Callarisa, L.; Rodriguez, R.M.; Moliner, M.A. Perceived value of the purchase of a tourism product. Tour. Manag. 2006, 27, 394-409. [CrossRef]

20. Duman, T.; Mattila, A.S. The role of affective factors on perceived cruise vacation value. Tour. Manag. 2005, 26, 311-323. [CrossRef]

21. Chen, X.H. Research on Competitive Advantages of Forest Ecotourism Scenic Spots Based on Tourist Perceived Value. Master's Thesis, Zhejiang University, Hangzhou, China, 2006.

22. Huang, Y.H.; Huang, F.C. Tourist perceived value model, measurement and empirical research. Tour. Trib. 2007, 22, 42-47. [CrossRef]

23. Wu, P.; Wang, C.L. Research on tourist perceived value based on web travel: A case study of Shanghai. Travel Forum 2016, 9, 34-39. [CrossRef]

24. Chen, C.F.; Tsai, D.C. How destination image and evaluative factors affect behavioral intentions? Tour. Manag. 2007, 28, 1115-1122. [CrossRef]

25. Lo, A.S.; Lee, C.Y. Motivations and perceived value of volunteer tourists from Hong Kong. Tour. Manag. 2011, 32, 326-334. [CrossRef]

26. Eid, R.; El-Gohary, H. The role of Islamic religiosity on the relationship between perceived value and tourist satisfaction. Tour. Manag. 2015, 46, 477-488. [CrossRef]

27. Rasoolimanesh, S.M.; Dahalan, N.; Jaafar, M. Tourists' perceived value and satisfaction in a community-based homestay in the Lenggong Valley World Heritage Site. J. Hosp. Tour. Manag. 2016, 26, 72-81. [CrossRef]

28. Tuan, Y.F. Topophilia: A Study of Environmental Perception, Attitudes, and Values; Prentice-Hall: Englewood Cliffs, NJ, USA, 1974.

29. Williams, D.R.; Roggenbuck, J.W. Measuring place attachment: Some preliminary results. NRPA Symp. Leis. Res. 1989, 9. Available online: https://www.fs.fed.us/rm/value/docs/nrpa89.pdf (accessed on 18 June 2018).

30. Huang, X.; Bao, J.; Wall, G. Place attachment: A research framework for the phenomenon of recreational behaviors. Tour. Trib. 2006, 21, 19-24. [CrossRef]

31. Williams, D.R.; Patterson, M.E.; Roggenbuck, J.W.; Watson, A.E. Beyond the commodity metaphor: Examining emotional and symbolic attachment to place. Leis. Sci. 1992, 14, 29-46. [CrossRef]

32. Gieryn, T.F. A space for place in sociology. Annu. Rev. Sociol. 2000, 26, 463-496. [CrossRef] 
33. Wang, S.; Chen, J.S. The influence of place identity on perceived tourism impacts. Ann. Tour. Res. 2015, 52, 16-28. [CrossRef]

34. Kyle, G.; Graefe, A.; Manning, R.; Bacon, J. Effects of place attachment on users' perceptions of social and environmental conditions in a natural setting. J. Environ. Psychol. 2004, 24, 213-225. [CrossRef]

35. Halpenny, E.A. Pro-environmental behaviours and park visitors: The effect of place attachment. J. Environ. Psychol. 2010, 30, 409-421. [CrossRef]

36. Yuksel, A.; Yuksel, F.; Bilim, Y. Destination attachment: Effects on customer satisfaction and cognitive, affective and conative loyalty. Tour. Manag. 2010, 31, 274-284. [CrossRef]

37. Zhu, F.; Wang, J.Z.; Wang, G. A Study on Relationship between the Place Dependence, Satisfaction and Revisit Intention -The Mediating Effect of Novelty Motivation. Bus. Res. 2015, 61, 180-187. [CrossRef]

38. Prayag, G.; Ryan, C. Antecedents of tourists' loyalty to Mauritius: The role and influence of destination image, place attachment, personal involvement, and satisfaction. J. Travel Res. 2012, 51, 342-356. [CrossRef]

39. Baker, D.A.; Crompton, J.L. Quality, satisfaction and behavioral intentions. Ann. Tour. Res. 2000, $27,785-804$. [CrossRef]

40. Cole, S.T.; Scott, D. Examining the mediating role of experience quality in a model of tourist experiences. J. Travel Tour. Mark. 2004, 16, 79-90. [CrossRef]

41. Haywood, K.M. Managing word of mouth communications. J. Serv. Mark. 1989, 3, 55-67. [CrossRef]

42. Huang, S.; Hsu CH, C. Effects of travel motivation, past experience, perceived constraint, and attitude on revisit intention. J. Travel Res. 2009, 48, 29-44. [CrossRef]

43. Pan, H. A Study on the Influence of the Image of HANGZHOU West Lake Tourist Attractions on the Behavioral Intention of Tourists in the World Cultural Heritage SITE. Master's Thesis, Anhui Normal University, Wuhu, China, 2015.

44. Liu, L.; $\mathrm{Wu}, \mathrm{H}$. Travel Motivations and Their Impact on Satisfaction and Behavioral Intentions of Korean Tourists: A Case of Jiuhua Mountain, China. Travel Forum 2010, 3, 147-152. [CrossRef]

45. Jang, S.C.S.; Feng, R. Temporal destination revisit intention: The effects of novelty seeking and satisfaction. Tour. Manag. 2007, 28, 580-590. [CrossRef]

46. Assaker, G.; Vinzi, V.E.; O'Connor, P. Examining the effect of novelty seeking, satisfaction, and destination image on tourists' return pattern: A two factor, non-linear latent growth model. Tour. Manag. 2011, 32, 890-901. [CrossRef]

47. Baloglu, S. An empirical investigation of attitude theory for tourist destinations: A comparison of visitors and nonvisitors. J. Hosp. Tour. Res. 1998, 22, 211-224. [CrossRef]

48. Lee, C.K.; Yoon, Y.S.; Lee, S.K. Investigating the relationships among perceived value, satisfaction, and recommendations: The case of the Korean DMZ. Tour. Manag. 2007, 28, 204-214. [CrossRef]

49. Pandža Bajs, I. Tourist perceived value, relationship to satisfaction, and behavioral intentions: The example of the Croatian tourist destination Dubrovnik. J. Travel Res. 2015, 54, 122-134. [CrossRef]

50. Chen, C.F.; Chen, F.S. Experience quality, perceived value, satisfaction and behavioral intentions for heritage tourists. Tour. Manag. 2010, 31, 29-35. [CrossRef]

51. Oh, H. Service quality, customer satisfaction, and customer value: A holistic perspective. Int. J. Hosp. Manag. 1999, 18, 67-82. [CrossRef]

52. Cronin, J.J., Jr.; Brady, M.K.; Hult, G.T. Assessing the effects of quality, value, and customer satisfaction on consumer behavioral intentions in service environments. J. Retail. 2000, 76, 193-218. [CrossRef]

53. Ji, H.Y. A Study on the Relationship among Perceived Value, Place Attachment and Environmentally Responsible Behavior: A Case Study on Zhongshan Scenic Area. Master's Thesis, Nanjing Agricultural University, Nanjing, China, 2016.

54. Chen, H.B. Study on Tourist' Revisit Intention from the Perspective of Customer Perceived Value. Master's Thesis, Hunan Normal University, Changsha, China, 2010.

55. Meng, Y. The Study of the Intergeneration Difference of Tourist Perceived Value of Qufu Confucius Museum. Master's Thesis, Southwestern University of Finance and Economics, Chengdu, China, 2013.

56. Yang, L. Study on Tourists' Perceived Value of Japan's Traditional Festivals. Unpublished Master's Thesis, Hunan Normal University, Changsha, China, 2013.

57. Wen-bing, L.I. Study on tourist loyalty model of ancient village: Based on the tourist perceived value and its dimensions. Geogr. Res. 2011, 30, 37-48. 
58. Sui, L.N.; Li, Y.K.; Chen, Y. A Study on the Value Differences of Tourists Visiting Cultural Heritages in Both China and Western Countries-A Case Study of Tourists in Xi'an. Tour. Trib. 2010, 25, 35-41. [CrossRef]

59. Han, C.X. Relationship of tourism perceived value, satisfaction and tourist behavioral intention. Hum. Geogr. 2015, 30, 137-144. [CrossRef]

60. Bai, K. A study on the relationship between place attachment and tourists' loyalty in rural tourism destinations: A case study of Agritainment of Chang'an District in Xi'an. Hum. Geogr. 2010, 1144, 120-125. [CrossRef]

61. Chung, J.Y.; Kyle, G.T.; Petrick, J.F.; Absher, J.D. Fairness of prices, user fee policy and willingness to pay among visitors to a national forest. Tour. Manag. 2011, 32, 1038-1046. [CrossRef]

62. Chen, J.T. Study on the Relationship among Tourism Involvement, Place Attachment and Tourist Loyalty. Master's Thesis, Hunan Normal University, Changsha, China, 2015.

63. Shou, D.Q. The Moderating Effect of Tourists' Novelty-Seeking on Revisit Intention over Time for Ancient Town Tourist Destination-Take Xitang Ancient Town as a Case. Master's Thesis, Nanjing University, Nanjing, China, 2017.

64. Zhang, H.; Wu, Y.; Buhalis, D. A model of perceived image, memorable tourism experiences and revisit intention. J. Destin. Mark. Manag. 2018, 8, 326-336. [CrossRef]

65. Jia, Y.J.; Lin, D.R. Tourists' perception of urban service, place attachment and loyal behaviors: A case study of Xiamen. Geogr. Res. 2016, 35, 390-400. [CrossRef]

66. Ding, F.Q.; Jiang, H.T.; Hou, S.Y.; Zhou, J. The influencing factors and mechanism on tourists' revisit intention of Chinese traditional ancient village-a case of Zhouzhuang. Hum. Geogr. 2015, 30, 146-152. [CrossRef]

67. Stylos, N.; Bellou, V.; Andronikidis, A.; Vassiliadis, C.A. Linking the dots among destination images, place attachment, and revisit intentions: A study among British and Russian tourists. Tour. Manag. 2017, 60, 15-29. [CrossRef]

68. Ursache, M. Tourism-significant driver shaping a destinations heritage. Procedia-Soc. Behav. Sci. 2015, 188, 130-137. [CrossRef]

69. Rodzi, N.I.; Zaki, S.A.; Subli, S.M. Between tourism and intangible cultural heritage. Procedia-Soc. Behav. Sci. 2013, 85, 411-420. [CrossRef]

70. Chen, Z.; Suntikul, W.; King, B. Constructing an intangible cultural heritage experiencescape: The case of the Feast of the Drunken Dragon (Macau). Tour. Manag. Perspect. 2020, 34, 100659. [CrossRef] 